\title{
Nickel-carbon nanocomposites prepared using castor oil as precursor: A novel catalyst for ethanol steam reforming
}

\author{
Neftalí L.V. Carreño ${ }^{a}$, Irene T.S. Garcia ${ }^{a}$, Cristiane W. Raubach ${ }^{a}$, Mateus Krolow ${ }^{a}$, \\ Cláudia C.G. Santos ${ }^{a}$, Luiz F.D. Probst ${ }^{\mathrm{b}}$, Humberto V. Fajardo ${ }^{\mathrm{c}, *}$ \\ a Departamento de Química Analítica e Inorgânica, Universidade Federal de Pelotas, 96010-900 Capão do Leão, RS, Brazil \\ b Departamento de Química, Universidade Federal de Santa Catarina, 88040-900 Florianópolis, SC, Brazil \\ c Departamento de Química, Universidade Federal de Ouro Preto, Instituto de Ciências Exatas e Biológicas, Campus Universitário s/n, Bauxita, $35400-000$ Ouro Preto, MG, Brazil
}

\section{A R T I C L E I N F O}

\section{Article history:}

Received 30 September 2008

Received in revised form 2 December 2008

Accepted 3 December 2008

Available online 7 December 2008

\section{Keywords:}

Castor oil

Nickel catalysts

Nanomaterials

Steam reforming

\begin{abstract}
A B S T R A C T
A novel and simple method to prepare nickel-based catalysts for ethanol steam reforming is proposed. The present method was developed using castor oil as a precursor. The results clarify that the nickel-carbon $(\mathrm{Ni} / \mathrm{C})$ catalyst has a high activity for ethanol steam reforming. It was observed that the catalytic behavior could be modified according to the experimental conditions employed. Moreover, it is interesting to note that the increase in the catalytic activity of the $\mathrm{Ni} / \mathrm{C}$ nanocomposite over time, at 500 and $600{ }^{\circ} \mathrm{C}$ of reaction temperature, may be associated with the formation of filamentous carbon. The preliminary results indicate that the novel methodology used, led to the obtainment of materials with important properties that can be extended to applications in different catalytic process.
\end{abstract}

(C) 2008 Elsevier B.V. All rights reserved.

\section{Introduction}

Hydrogen is considered as the fuel of the future. The use of hydrogen for fuel cell applications represents one of the most environmentally sound methods for the conversion, with high efficiency, of chemical energy into electrical energy [1]. Several routes are available for hydrogen production, including water electrolysis, partial oxidation and steam reforming of hydrocarbons and alcohol reactions, with methane steam reforming being the most commonly used and economic route [2]. An attractive alternative, however, is catalytic ethanol steam reforming Eq. (1).

$\mathrm{C}_{2} \mathrm{H}_{5} \mathrm{OH}+3 \mathrm{H}_{2} \mathrm{O} \rightarrow 2 \mathrm{CO}_{2}+6 \mathrm{H}_{2}$

Ethanol has several advantages compared to other raw materials, but the most important is its renewable origin. In addition, ethanol has relatively high hydrogen content, and its reaction with water under steam reforming conditions has been shown to be entirely feasible from a thermodynamic point of view [3-5]. However, the success of the process is dependent on the choice of the catalytic system. Several catalysts have been proposed to be further considered for practical applications in this reaction, using different metals (noble and non-noble) and supports. Nickel seems to be the preferred active ingredient because of its high activity and low cost, in spite of the possibility of coke formation as well as metal

\footnotetext{
* Corresponding author. Tel.: +55 3135591230.

E-mail address: hfajardo@iceb.ufop.br (H.V. Fajardo).
}

sintering, leading to considerable performance degradation during long-term operation [3-5]. Thus, research on novel nickel-based catalyst systems is an important challenge.

An economical and environmentally friendly alternative is to prepare catalysts from renewable resources, for example, through the use of low-cost biomass derived feedstocks. Thus, castor oil was chosen as the material to be used as a precursor of a new catalyst. The oil is obtained from extracting or expressing the seed of the plant Ricinus communis of the family Eurphorbiacae. The castor plant is available at low cost and grows in the wild in large quantities in most tropical and sub-tropical countries, such as Brazil, which is one of the world's largest exporters of the oil. Castor oil consists mainly of esters of 12-hydroxy-9-octadecenoic acid (ricinoleic acid) and other fatty acids in minor quantities, thus the presence of hydroxyl groups and double bonds makes the oil suitable for many chemical reactions and modifications. The components of castor oil are given in Table 1 [6].

The preliminary results show the obtainment, through a simple chemical process, of a new $\mathrm{Ni} / \mathrm{C}$ nanocomposite with potential catalytic properties, showing the possibility to increase the added value of castor oil trough it use as a precursor of the new catalyst.

\section{Experimental}

\subsection{Sample preparation}

The Ni/C catalyst was obtained through the use of castor oil as the precursor of the support by adding lauryl ether sodium sulfate as a 
Table 1

Various fatty acids of the castor oil.

\begin{tabular}{lc}
\hline Acids & $(\%)$ \\
\hline Ricinoleic acid & $84-91$ \\
Oleic acid & $3-6$ \\
Linoleic acid & $3-6.5$ \\
Stearic acid & $1.5-2$ \\
Palmitic acid & $0.5-1.5$ \\
Dihydroxystearic acid & $0.5-1$ \\
Linolenic acid & $0.3-0.5$ \\
Eicosanoic acid & $0.3-0.5$ \\
\hline
\end{tabular}

surfactant and nickel nitrate $\left(\mathrm{Ni}\left(\mathrm{NO}_{3}\right)_{2} \cdot 6 \mathrm{H}_{2} \mathrm{O}\right.$, Fluka) as a precursor of the active metal phase. The salt solution of the metal cation was added to a solution of the castor oil containing the surfactant. The system was homogenized at $80^{\circ} \mathrm{C}$ forming a viscous resin. The resin was thermally treated in a muffle oven under an oxidizing atmosphere at $350^{\circ} \mathrm{C}$ for $1 \mathrm{~h}$. The material was then calcined at $500^{\circ} \mathrm{C}$ for $2 \mathrm{~h}$ under nitrogen atmosphere. A typical flowchart for the synthesis method is shown in Fig. 1.

The castor plant, from which the oil was extracted in order to obtain the catalyst, was cultivated in Pelotas, RS, Brazil.

\subsection{Sample characterization}

The structural analysis of the $\mathrm{Ni} / \mathrm{C}$ sample was carried out by $\mathrm{X}$-ray diffraction (XRD, Rigaku D-Max 2500) using $\mathrm{Cu} \mathrm{K} \alpha$ radiation and a graphite monochromator.

The structure and morphology of the samples were verified by transmission electron microscopy (TEM) (Jeol, model 3010, operated at $300 \mathrm{KV}$ ) equipped with X-ray energy dispersive spectroscopy.

The specific surface area (BET method) of the sample was determined by $\mathrm{N}_{2}$ adsorption/desorption isotherms at liquid nitrogen temperature by means of an Autosorb-1C analyzer (Quantachrome Instruments).

Temperature programmed reduction (TPR) analysis was performed in a quartz reactor under $5 \mathrm{vol} \% \mathrm{H}_{2} / \mathrm{N}_{2}$ flow $\left(30 \mathrm{~mL} \mathrm{~min}^{-1}\right.$ )

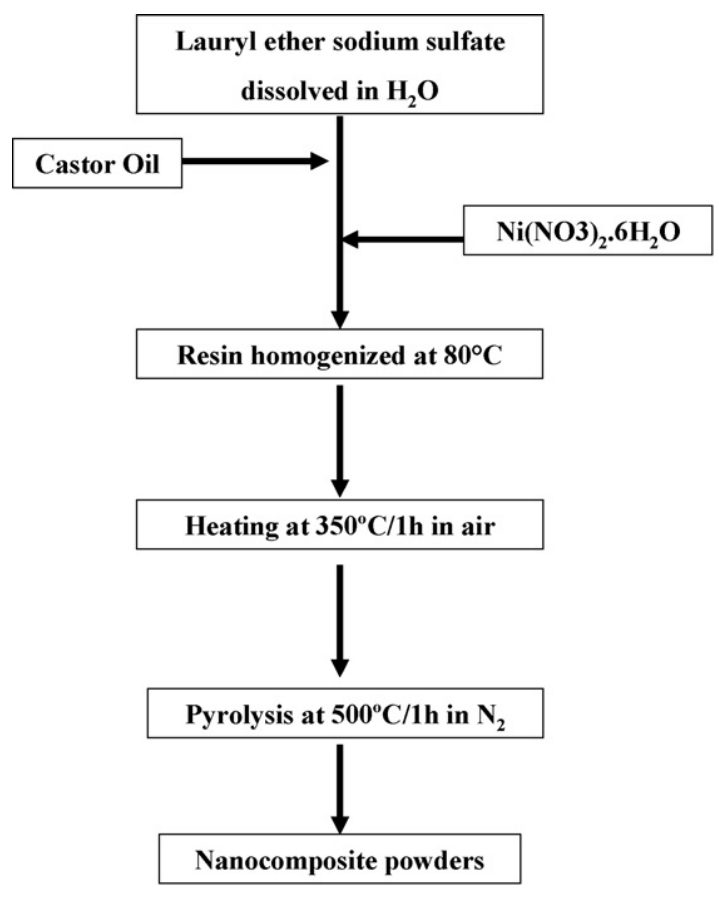

Fig. 1. Flowchart for the synthesis of the Ni/C catalyst. from 30 to $920^{\circ} \mathrm{C}$ at a heating rate of $5^{\circ} \mathrm{C} \mathrm{min}^{-1}$. A thermal conductivity detector was used to follow the $\mathrm{H}_{2}$ consumption.

\subsection{Catalytic testing}

Catalytic performance tests were conducted at atmospheric pressure with a quartz fixed-bed reactor fitted in a programmable oven, at temperatures of 400,500 and $600^{\circ} \mathrm{C}$. The water:ethanol mixture (molar ratio 3:1) was pumped into a heated chamber and vaporized. The water-ethanol gas $\left(\mathrm{N}_{2}\right)$ stream $\left(30 \mathrm{~mL} \mathrm{~min}^{-1}\right)$ was then fed to the reactor containing $100 \mathrm{mg}$ of the catalyst. The catalyst was previously treated in situ under hydrogen atmosphere at $600{ }^{\circ} \mathrm{C}$ for $2 \mathrm{~h}$. The reactants and the composition of the reactor effluent were analyzed with a gas chromatograph (Shimadzu GC $8 \mathrm{~A}$ ), equipped with a thermal conductivity detector, a Porapak-Q and a $5 \mathrm{~A}$ molecular sieve column with Ar as the carrier gas. Reaction data were recorded for $5 \mathrm{~h}$.

\section{Results and discussion}

The material had a relatively low specific surface area value, $55 \mathrm{~m}^{2} \mathrm{~g}^{-1}$. Carbon-based materials, usually, have high surface area values, however, in this case, the high amount of nickel used and the heat treatment process employed, might have influenced this final textural property of the $\mathrm{Ni} / \mathrm{C}$ sample. With the aim of identifying the phases present in the sample, XRD and TPR analysis were carried out. Fig. 2 shows the XRD patterns of the fresh Ni/C catalyst.

The presence of nickel oxide and metallic nickel phases was verified. According to the literature, the peaks at $2 \theta=37^{\circ}, 44^{\circ}$ and $64^{\circ}$ can be attributed due to the $\mathrm{NiO}$ phase, however, the peaks at $2 \theta=45^{\circ}$ and $53^{\circ}$ can be assigned to metallic nickel, which represent the indices of (111) and (200) crystalline planes, respectively. The formation of metallic nickel during the pyrolysis process under $\mathrm{N}_{2}$ flow might be due to residual carbon. In such an environment, carbon can act as an internal reduction agent promoting the formation of the metallic species. The presence of residual carbon should be observed in the angular region between $20^{\circ}$ and $40^{\circ}$, however the weak sign observed could be due to interference of the nickel phase peaks which are very intense [7,8]. The TPR profile of the nickel-based sample is shown in Fig. 3. The $\mathrm{H}_{2}$ consumption peak in the range of $220-450^{\circ} \mathrm{C}$, with a maximum at $390^{\circ} \mathrm{C}$, is due to the $\mathrm{NiO}$ reduction [9].

Fig. 4 shows the TEM images of the Ni/C sample, showing metal particles embedded and dispersed within the carbon matrix. It can be observed that although the TEM images show metallic particles,

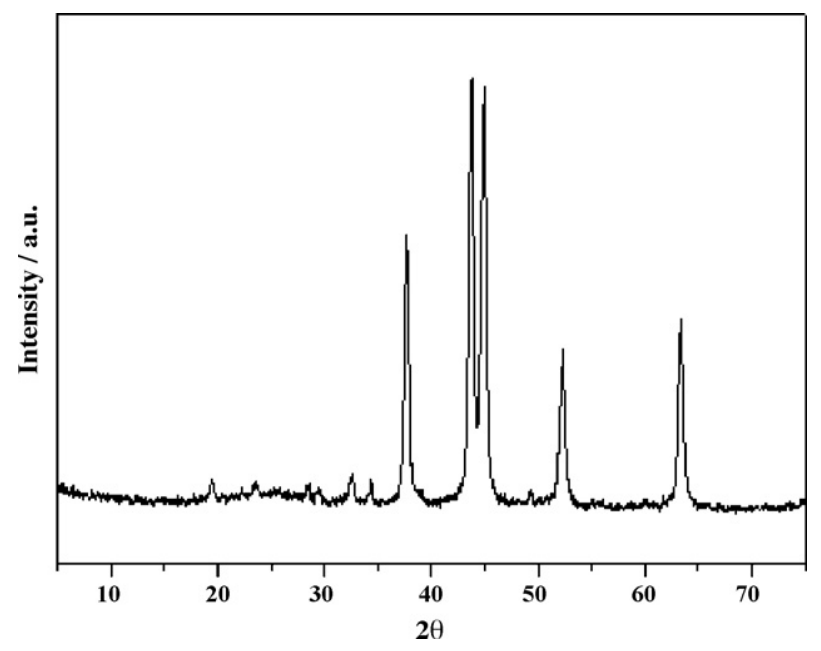

Fig. 2. X-ray diffraction pattern of $\mathrm{Ni} / \mathrm{C}$ catalyst after annealing process. 


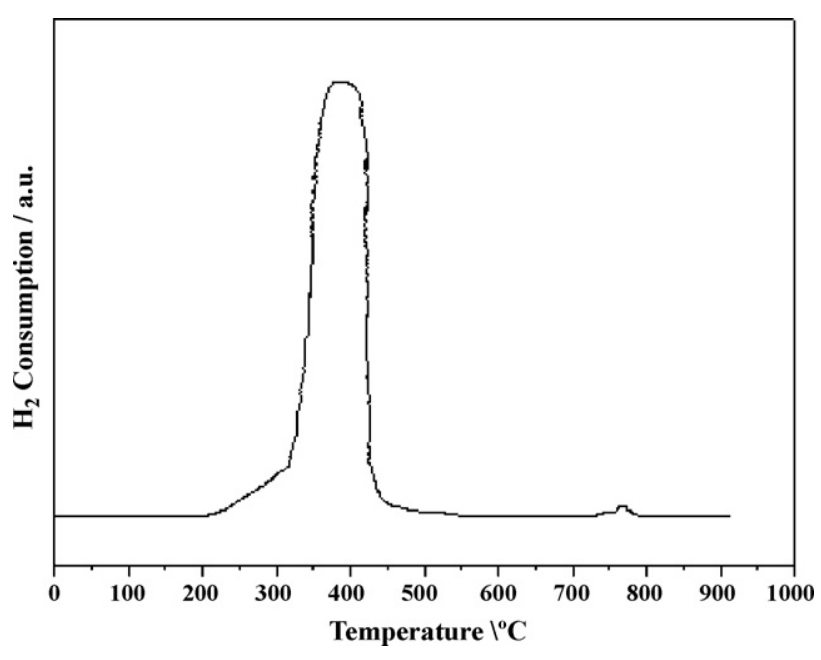

Fig. 3. Temperature programmed reduction profile of $\mathrm{Ni} / \mathrm{C}$ catalyst.

they do not allow a clear distinction between $\mathrm{Ni}$ and $\mathrm{NiO}$ particles, however, they confirm the nanometric character of the particles. The nanometric character of the nickel particles may be due to the defects caused by the presence of the amorphous carbon in the catalyst, since the sample was heat treated under $\mathrm{N}_{2}$ atmosphere, and thus the presence of carbon is very significant. The carbon can act as a physical barrier, impeding or hindering the sinterization process of the metallic particles.

In order to investigate the catalytic activity of the $\mathrm{Ni} / \mathrm{C}$ sample, the steam reforming of ethanol was carried out. Typical experimental results obtained are shown in Fig. 5, in which the selectivity of each product and the conversion of ethanol are shown as a function of reaction temperature. As expected, the conversion of ethanol increased with increasing reaction temperature. The reaction pathway during catalytic ethanol steam reforming comprises a series of simultaneous reactions, including decomposition, dehydrogenation, dehydration and steam reforming reactions. These reactions are more or less promoted depending on the nature of the catalyst, the type of interaction with the surface of the solid material and the different reaction conditions [3-5]. At a reaction temperature of $400{ }^{\circ} \mathrm{C}$, the main products detected were acetaldehyde, hydrogen, carbon monoxide and methane, indicating that ethanol dehydrogenation Eq. (2) and decomposition Eq. (3) reactions occurred.
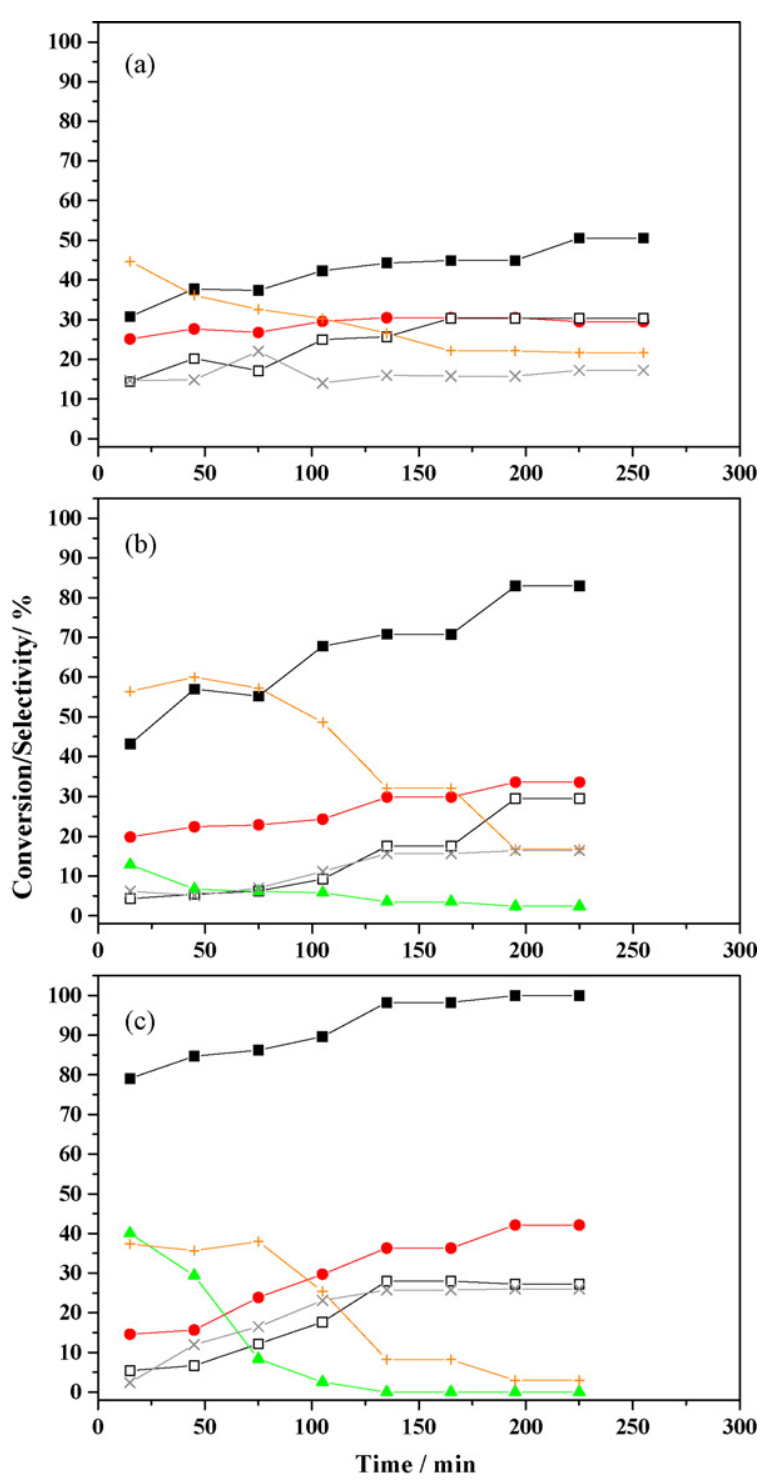

Fig. 5. Catalytic behavior of $\mathrm{Ni} / \mathrm{C}$ in ethanol steam reforming at different temperatures: (a) 400 , (b) 500 and (c) $600^{\circ} \mathrm{C}$. Legends: $=\mathrm{C}_{2} \mathrm{H}_{5} \mathrm{OH}$ conversion and $\mathrm{O}=\mathrm{H}_{2}$; $\Delta=\mathrm{C}_{2} \mathrm{H}_{4} ;+=\mathrm{CH}_{3} \mathrm{CHO} ; \square=\mathrm{CH}_{4} ; x=\mathrm{CO}$, selectivities.
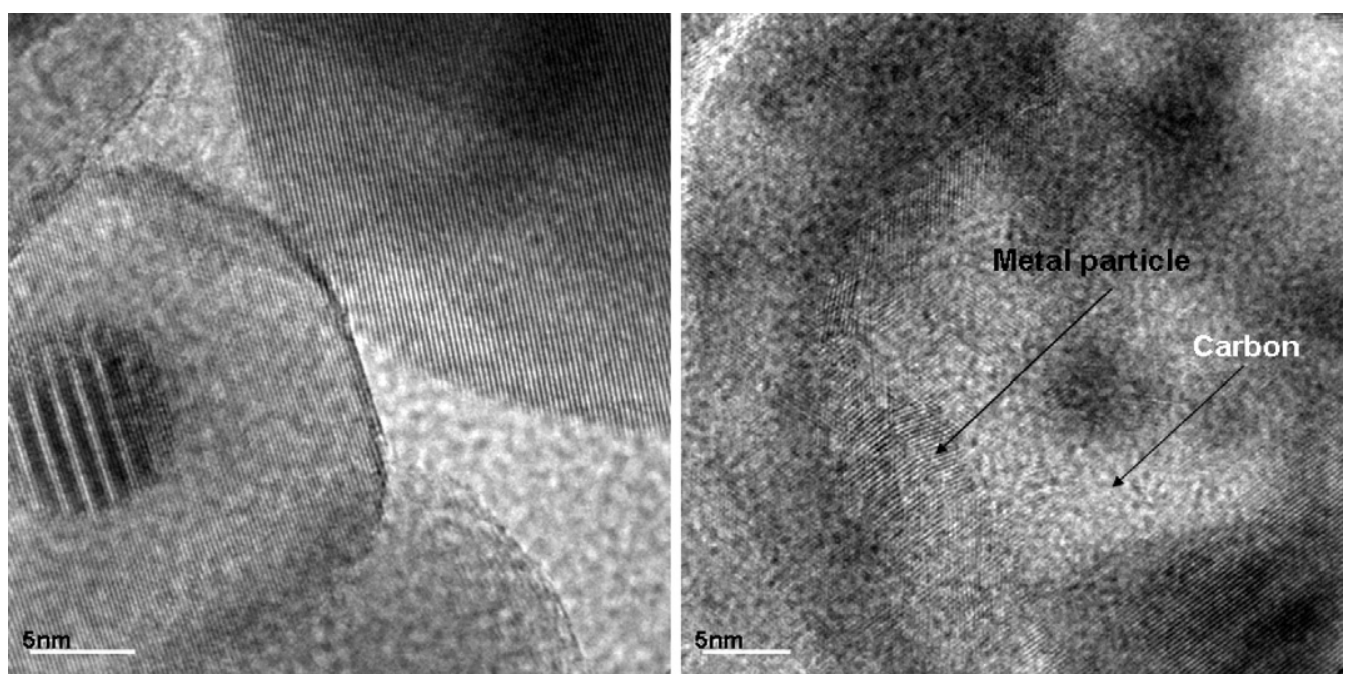

Fig. 4. Transmission electron microscopy images of $\mathrm{Ni} / \mathrm{C}$ catalyst before catalytic test. 

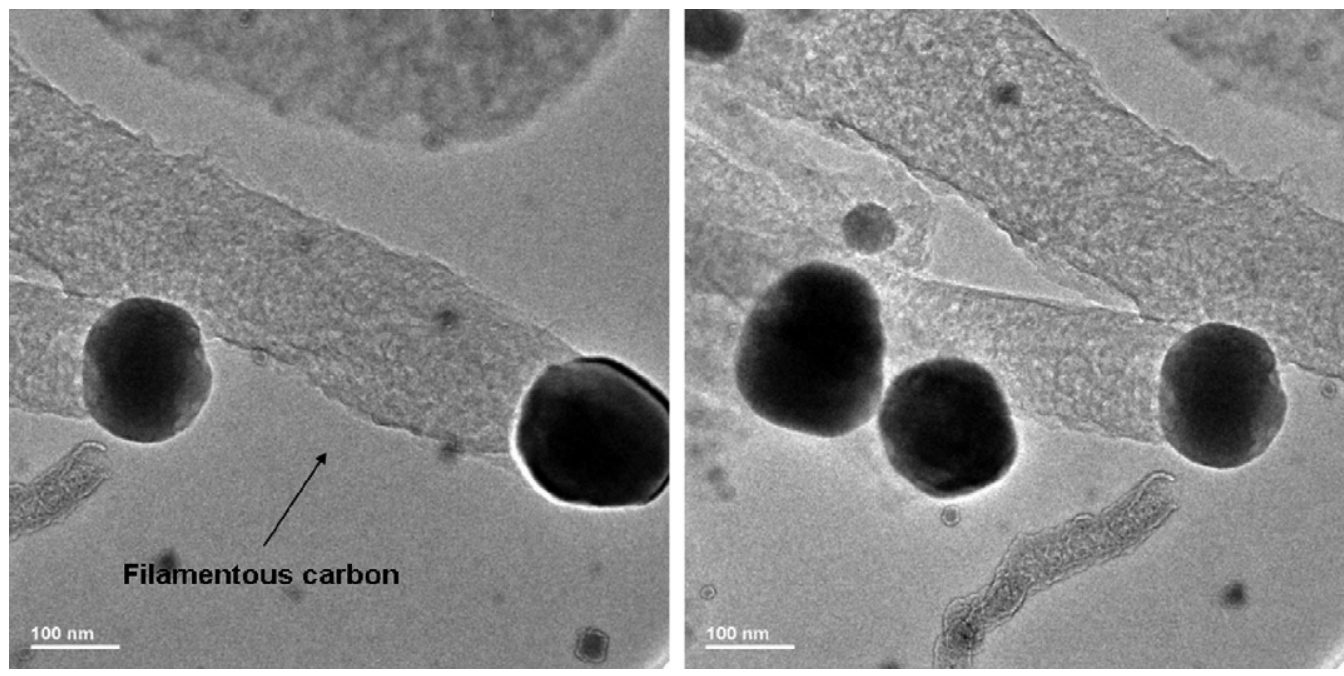

Fig. 6. Transmission electron microscopy images of $\mathrm{Ni} / \mathrm{C}$ catalyst after catalytic test at $500^{\circ} \mathrm{C}$.

$$
\begin{aligned}
& \mathrm{C}_{2} \mathrm{H}_{5} \mathrm{OH} \rightarrow \mathrm{CH}_{3} \mathrm{CHO}+\mathrm{H}_{2} \\
& \mathrm{C}_{2} \mathrm{H}_{5} \mathrm{OH} \rightarrow \mathrm{CH}_{4}+\mathrm{CO}+\mathrm{H}_{2}
\end{aligned}
$$

When the process was carried out at 500 and $600^{\circ} \mathrm{C}$, an interesting catalytic behavior could be observed. Ethanol conversion increased with time on stream. At $600^{\circ} \mathrm{C}$, the conversion of ethanol reached $80 \%$ at the beginning of the test, and increased to $100 \%$ after $150 \mathrm{~min}$. The complete conversion of ethanol is an important factor to the entire process be considered economically attractive. The increase in the reaction temperature led to a decrease in the $\mathrm{H}_{2}, \mathrm{CO}$ and $\mathrm{CH}_{4}$ selectivities and an increase in the selectivity of $\mathrm{CH}_{3} \mathrm{CHO}$, as well as the formation of $\mathrm{C}_{2} \mathrm{H}_{4}$. This indicates that ethanol dehydrogenation and dehydration Eq. (4) reactions were favored at the beginning of the test.

$\mathrm{C}_{2} \mathrm{H}_{5} \mathrm{OH} \rightarrow \mathrm{C}_{2} \mathrm{H}_{4}+\mathrm{H}_{2} \mathrm{O}$

However, over time, the selectivity values of acetaldehyde and ethylene decreased while the selectivity values of $\mathrm{H}_{2}, \mathrm{CO}$ and $\mathrm{CH}_{4}$ increased considerably, indicating that at this stage the ethanol decomposition Eq. (3) is the main reaction involved. The acetaldehyde Eq. (5) and ethylene Eq. (6) decomposition reactions may also be occurring, since an increase in $\mathrm{H}_{2}$ and $\mathrm{CH}_{4}$ selectivities was observed and $\mathrm{CO}$ selectivity remains almost constant, most notably when the process was carried out at $500^{\circ} \mathrm{C}$.

$\mathrm{CH}_{3} \mathrm{CHO} \rightarrow \mathrm{CH}_{4}+\mathrm{CO}$

$\mathrm{C}_{2} \mathrm{H}_{4} \rightarrow 2 \mathrm{C}+2 \mathrm{H}_{2}$

One of the main challenges for the industrial use of ethanol steam reforming catalysts is related to carbon depositions on the catalyst surfaces, formed during the process leading to catalyst deactivation [3-5]. The routes of carbon formation include several reactions, and ethylene polymerization is of particular importance. A lot of different parameters influence the carbon formation, such as reaction temperature, inlet steam/carbon ratio and the surface structure of the catalytic material. The catalyst deactivation depends not only on the amount of carbon deposited but also on other factors, such as the nature of the deposited carbon, and it occurs predominantly through covering of the active phase due to the encapsulating carbon [8-13]. A great carbon formation during the process may increase the pressure drop, crush the catalyst, block the active surface and even form at the inner perimeter of the reforming tubes resulting in a lower heat transfer. These situations can difficult or disable a current operation since the regeneration or separation of catalysts has not shown to be feasible easily. Nevertheless, carbon may deposit over catalysts without direct deactivation, in a mechanism that results in the formation of filamentous carbon. It has been reported that the formation of this type of carbon can result in a better catalyst activity performance [12-14]. The high amount of carbon formation, visually detected after our experiments, and the increase of ethanol conversion observed is a strong indication of the predominant formation of filamentous carbon, and not encapsulating carbon. The catalytic material after the reaction was analyzed by TEM. The TEM images (Fig. 6) show filamentous carbon formation. This can perhaps explain why the $\mathrm{Ni} / \mathrm{C}$ catalyst presented an increase in ethanol conversion with time. Filamentous carbon is a result of carbon atoms adsorbed on a nickel particle, which diffuse and nucleate into a carbon fiber. In the process, most of the nickel crystals remain available for catalysis and only some are blocked by the growing carbon fibers.

\section{Conclusions}

In this study, a promising method for obtaining a nickel-based catalyst was developed. The results clarify that the Ni/C catalyst has a high activity for ethanol steam reforming and the reaction conditions influenced the process. Acetaldehyde seems to be an intermediate product formed, which may be further decomposed producing $\mathrm{H}_{2}, \mathrm{CH}_{4}$ and $\mathrm{CO}$. Moreover, it is interesting to note that the increase in the catalytic activity with time, presented by the catalyst at 500 and $600^{\circ} \mathrm{C}$, may be associated with the formation of filamentous carbon. These preliminary results indicate that the novel methodology used in the preparation led to the obtainment of materials with important properties that can be extended to applications in different catalytic process.

\section{Acknowledgments}

Financial support by FINEP and CNPq is gratefully acknowledged.

\section{References}

[1] F. de Bruijn, Green Chem. 7 (2005) 132-150.

[2] R. Kothari, D. Buddhi, R.L. Sawhney, Renew. Sust. Energy Rev. 12 (2008) 553-563.

[3] A. Haryanto, S. Fernando, N. Murali, S. Adhikari, Energy Fuels 19 (2005) 2098-2106.

[4] P.D. Vaidya, A.E. Rodrigues, Chem. Eng. J. 117 (2006) 39-49.

[5] M. Ni, D.Y.C. Leung, M.K.H. Leung, Int. J. Hydrogen Energy 32 (2007) 3238-3247.

[6] D.S. Ogunniyi, Bioresour. Technol. 97 (2006) 1086-1091. 
[7] A. Valentini, N.L.V. Carreño, L.F.D. Probst, E.R. Leite, E. Longo, Micropor. Mesopor. Mater. 68 (2004) 151-157.

[8] A. Valentini, N.L.V. Carreño, L.F.D. Probst, A. Barison, A.G. Ferreira, E.R. Leite, E. Longo, Appl. Catal. A 310 (2006) 174-182.

[9] J.A. Rodriguez, J.C. Hanson, A.I. Frenkel, H.Y. Kim, M. Perez, J. Am. Chem. Soc. 124 (2002) 346-354.

[10] J.R. Rostrup-Nielsen, J. Sehested, J.K. Norskov, Adv. Catal. 47 (2002) 65-139.
[11] D.L. Trimm, Catal. Today 49 (1999) 3-10.

[12] A.L. Alberton, M.M.V.M. Souza, M. Schmal, Catal. Today 123 (2007) 257264.

[13] J. Rass-Hansen, C.H. Christensen, J. Sehested, S. Helveg, J.R. Rostrup-Nielsen, S. Dahl, Green Chem. 9 (2007) 1016-1021.

[14] M.M.V.M. Souza, L. Clavé, V. Dubois, C.A.C. Perez, M. Schmal, Appl. Catal. A 272 (2004) 133-139. 